\title{
Towards A Smart Campus: From Basemap to Sensors
}

\author{
Wilkening, Jan ${ }^{\mathrm{a},} *$, Schäffner, Rainer ${ }^{\mathrm{b}}$ \\ ${ }^{a}$ University of Applied Sciences Würzburg-Schweinfurt e-mail: jan.wilkening@fhws.de \\ ${ }^{b}$ University of Applied Sciences Würzburg-Schweinfurt e-mail: rainer.schaeffner@fhws.de \\ * Corresponding author
}

Keywords: Campus Mapping, 3D Visualization, Indoor Mapping

\begin{abstract}
:
University campuses are very interesting research objects for cartographers, GIS and mapping professionals for many reasons. One reason is that many people have to orient on campuses and need maps for navigation, especially when they are on-campus for the first time. While existing online mapping platforms facilitate routing between addresses on street networks, they are not suitable for finding certain buildings, rooms or facilities "behind" this address (Wilkening et al., 2018). In general, publicly available maps of buildings are hard to find.
\end{abstract}

To tackle this problem, several universities have created maps or even interactive information systems for different audiences such as visitors, staff, students (see Wilkening et al, 2019). One mentionable example is the campus information system (CIS) at the University of Applied Sciences in Würzburg, which has been developed by the GIS team of the university's Department of Surveying since 2015. The current version of the CIS is available as a web application on the university's website makes it easy for different audiences to find rooms in different buildings on the campus.

At the time of writing, the CIS consists of an interactive 3D visualization of the campus, a database that can be queried to find rooms, people and facilities, and a routing network than can be used to calculate the fastest route between two positions (see Figure 1). The system was built with ArcGIS Server services and the JavaScript API for ArcGIS. No CAD and floor plans were used for creating the initial data model for the basemap. All the data that build the foundation for mapping and spatial analysis were digitized in GIS programs, mostly within student projects.

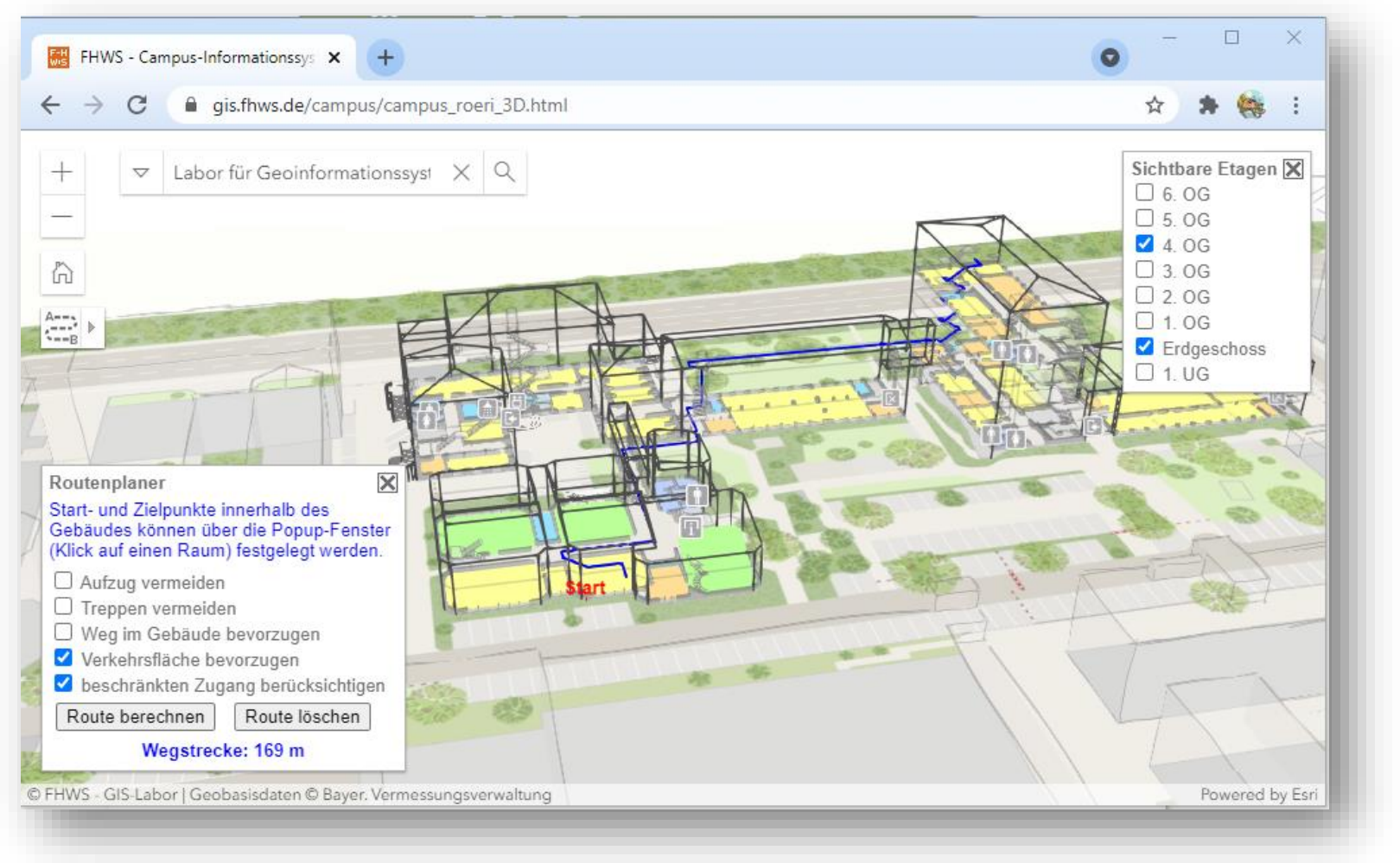

Figure 1. Current state of the CIS for one university campus (https://gis.fhws.de/campus/campus_roeri_3D.html). 
While CAD can easily be transferred to GIS data in Desktop GIS, we generally suggest to take care when using CAD plans as a foundation for a basemap. The reason is that it is often more work to convert CAD data to GIS data than creating the data from scratch on-site or in front of a GIS. However, this depends on the amount of space that has to be digitized and on the quality of the CAD plans.

After creating the information model and the basemap for the campus, a CIS can be enhanced and extended in several ways.

At our campus, two additional bachelor theses focused on transferring the system to Esri's new ArcGIS Indoors platform. One thesis in 2020 focused on creating a new data model for ArcGIS Indoors, while in 2021 another bachelor student investigated indoor positioning with Bluetooth beacons in different buildings on the campus. Indoor positioning is an important functionality for CIS, since most routing tasks start from your current position, which can easily be identified with the popular "blue dot" on smartphones and tablets (see Figure 2).
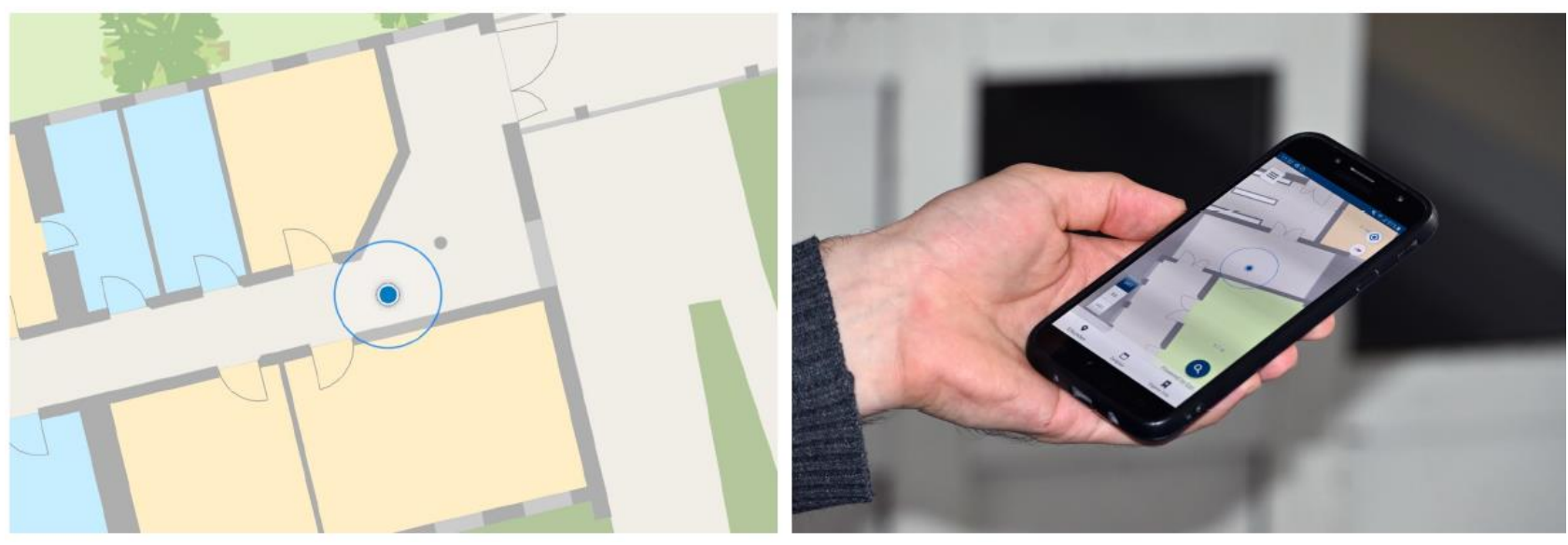

Figure 2. Indoor positioning on mobile devices.

Besides data models and routing for indoor spaces, another enhancement of the current CIS is the integration of sensors. Another ongoing bachelor thesis investigates outdoor sensors such as senseBoxes (sensebox.de), which can measure light intensity, room temperature or humidity and transfer the measurements to the CIS. In 2018, a bachelor thesis has investigated people counters in rooms with indoor systems, which can convey information about available workplaces in computer rooms. The most important values of these sensor measurements can be processed by GeoEvent Server and easily be communicated in interactive dashboards. In this context, privacy issues are especially important. It has to be mentioned that not everything that is technically possible can or should be implemented in a publicly available CIS.

Further work packages for the CIS include integrating external information such as social media, the schedule of lecture rooms or the menu of the refectory. The goal is to eventually create a Smart Campus Information System, which cannot only display data, but also help in making smart decisions to use resources more efficiently.

Our university collaborates with other universities in Austria and Switzerland to exchange ideas on a common data hub (https://edc-dach-esridech.hub.arcgis.com/). Examples from the ETH Zurich, which are featured on this data hub, include gaze-controlled Campus Maps and an indoor navigation system for Microsoft HoloLens 2. We invite other universities to join our example and to collaborate to create innovative Smart Campus projects.

\section{References}

Wilkening, J., Schäffner, R. \& Staub, T. (2018): Interaktiver 3D-Routenplaner für den Campus Röntgenring in Würzburg. In: Strobl, J., B. Zagel, G. Griesebner \& T. Blaschke (eds.): AGIT - Journal für Angewandte Geoinformatik 4-2018, pp. 35-40.

Wilkening, J., Kapaj, A. \& Cron, J. (2019): Creating a 3D Campus Routing Information System with ArcGIS Indoors. Dreiländertagung der DGPF, der OVG und der SGPF in Wien, Österreich-Publikationen der DGPF, Band 28, 2019. 